\title{
FACTORS AFFECTING KARST SPRING TURBIDITY IN EASTERN WASHINGTON COUNTY, MARYLAND
}

\author{
David K. Brezinski \\ Maryland Geological Survey, 2300 St.Paul Street, Baltimore, Maryland,21218,david.brezinski@maryland.gov
}

Johanna M. Gemperline

Maryland Geological Survey, 2300 St. Paul Street, Baltimore, Maryland, 21218, johanna.gemperline@maryland.gov

Rebecca Kavage Adams

Maryland Geological Survey,2300 St.Paul Street, Baltimore, Maryland,21218,rebecca.adams@maryland.gov

David W. Bolton

Maryland Geological Survey, 2300 St. Paul Street, Baltimore, Maryland, 21218, david.bolton@maryland.gov

\begin{abstract}
Infrequent and episodic turbidity events within the karst spring at the Albert Powell Trout Hatchery in Maryland's eastern Great Valley threatened late winter fry populations. Turbidity events in early winter 2016-2017 prompted detailed geologic, dye tracing, and resistivity studies. The hatchery spring lies at the juncture of a northeast trending thrust fault and a northwest trending cross strike fault. Dye tracing study along these structures produced mixed results. Fluorescein tracing, injected $1,500 \mathrm{~m}$ north, and upstream of the spring was used to test the conductivity along the Beaver Creek fault and Beaver Creek. This dye was not conclusively identified at any of the surrounding recovery sites. Rhodamine WT injected more than a kilometer northwest of the spring, and along the trend of the cross fault, was detected at both the hatchery spring and surrounding recovery sites after about one week. 2D resistivity studies attempting to identify subsurface voids along the cross-fault trend show a high resistivity anomaly possibly indicating an air-filled void and warrant further investigation. The study suggests that while faulting plays a role in direction of ground water movement, turbidity events appear to be most prone during periods of lowered flow.
\end{abstract}

\section{Introduction}

The Albert Powell Hatchery (APH), located along Beaver Creek near the eastern edge of Maryland's Great Valley, raises over 250,000 rainbow trout each year for stocking of the State's freshwater streams. A karst spring that is the main water supply for the hatchery has a flow of up to 4000 gallons per minute ( 908 cubic meters per hour) (James and others, 1999). Since its founding in 1949, infrequent and episodic turbidity events have killed or threatened several late winter fry populations. Two such episodes, in November 2004, resulted in significant mortality to young fish. Following these events, the Maryland Geological Survey (MGS) conducted a study to determine the possible catchment area that might contribute water, as well as sediment, to the spring (Duigon, 2009). That study indicated that the groundwater divide doesn't coincide with the surface-water divide, and that the contributing area is partly controlled by faulting. On December 5, 2016, the hatchery spring again experienced a major turbidity event that did not result in fish mortality. A second smaller turbidity event was recorded on January 16, 2017. Following the December 2016 event the Maryland Geological Survey and the Maryland Department of the Environment (MDE) identified two possible surface sources of sediment input nearby. The dye tracing portion of this study was conducted to evaluate if either of the sites was hydrologically connected to the hatchery spring. Additionally, an electrical resistivity study along the northwest trending cross fault was conducted to identify any subsurface voids along that structure.

\section{Location and Geology}

The spring that supplies water to the APH is located near the eastern edge of the Hagerstown Valley. The Hagerstown Valley is the largest karst region in Maryland and is a segment of the Great Valley Section of the Ridge and Valley Province (Reger and Cleaves, 2008) (Figure 1). The geology of the area surrounding the APH spring has been mapped in (Brezinski and Fauth, 2009; Brezinski and Bell, 2009) (Figure 1). 


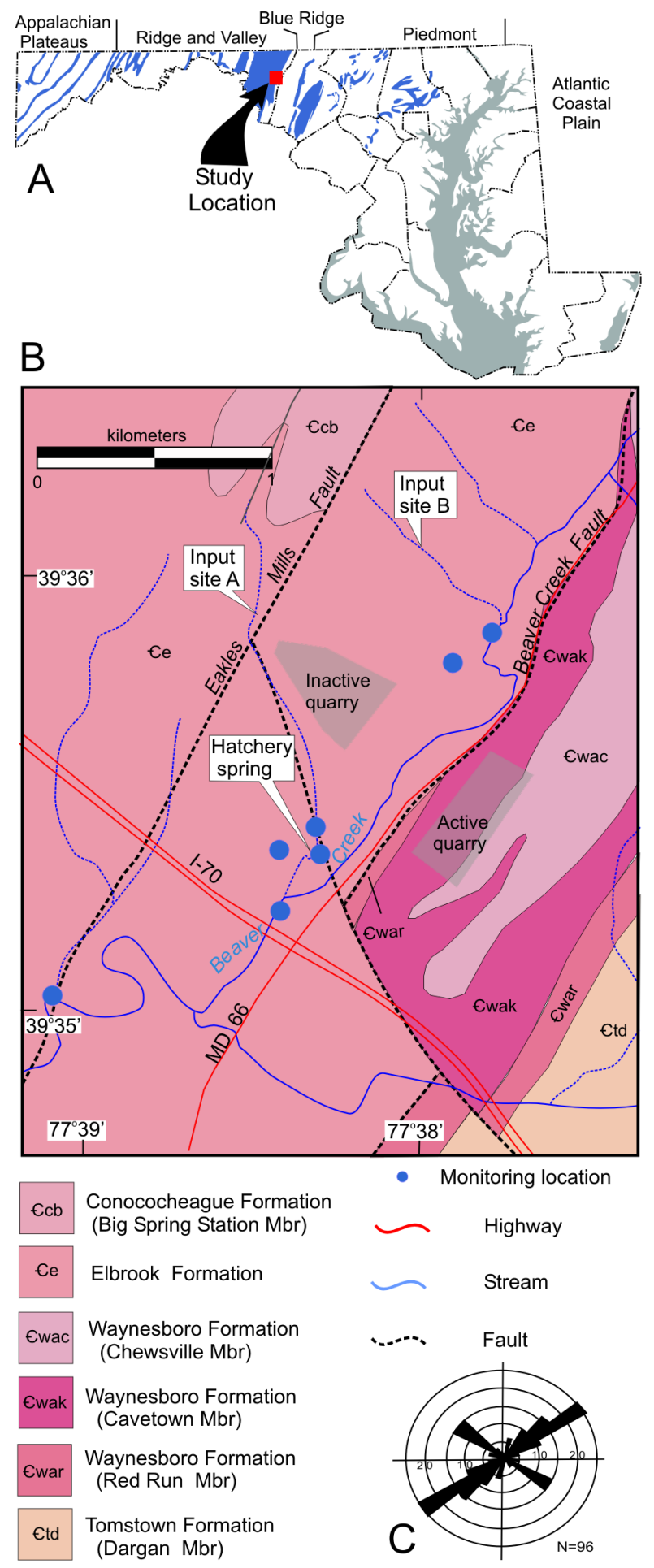

The spring lies at the junction of two mappable fault traces. Stretching northeast from the spring, a thrust fault termed the Beaver Creek fault (Brezinski, 1992), places Lower Cambrian carbonate and clastic rocks of the Waynesboro Formation over shaly limestone of the Middle Cambrian Elbrook Formation. Near APH the Beaver Creek fault is truncated by a northwest trending unnamed high-angle cross strike fault that offsets the Waynesboro outcrop belt by approximately $900 \mathrm{~m}$. This cross-strike structure has been portrayed as passing directly through the APH spring and continuing up a karst valley to the northwest of the spring (Brezinski and Bell, 2009). Near the western edge of the study area a high angle fault termed the Eakles Mills fault (Brezinski, 1992) has been interpreted as intersecting the cross fault, and was initially believed to be in karst connectivity with both the cross fault and Beaver Creek to the southwest of APH (Brezinski and Bell, 2009) (Figure 1). Based on these structural factors dye tracing and resistivity studies were conducted to determine if either of these structures influenced turbidity within the APH spring.

Two quarries, Beaver Creek West and East, lie approximately $0.5 \mathrm{~km}$ northeast and east of the APH, respectively. Beaver Creek West has been inactive since 2008. Beaver Creek East, although currently operating, lies east of a groundwater divide that follows the trace of the Beaver Creek Fault, which is believed to act as a barrier to groundwater flow (Water level monitoring data, 2004, unpublished).

\section{Methods}

To determine background levels of fluorescence, water samplers and charcoal traps were placed prior to dye injection. Two injection sites were chosen for the dye tracing study. At one of the injections sites fluorescein was injected and at the second rhodamine WT was used (Figure 1B). The automatic water samplers (ISCO ${ }^{\text {TM }}$ samplers) were placed at three locations for six days and activated charcoal traps were placed, in pairs, at eight sites for approximately one month.

Figure 1. A, Location map of karst regions of Maryland (blue), the study area (red square) and the Hagerstown (Great) Valley. $B$, Geologic map of study area at the Albert Powell Trout Hatchery with locations of dye injection and monitoring. C, Rose diagram showing fracture orientations for measured joints at the Beaver Creek West Quarry.

Dye was injected at the two study sites on Monday, February 27, 2017, after background water samples and charcoal traps had been collected. At the first site, fluorescein dye was injected in recently formed holes within a field 1,500 $\mathrm{m} \mathrm{NNE}$ of the main spring. At this site, reclaimed earth was being used to make the field easier to farm. The injection hole was flushed with water. After 
observing the water sink into the ground, approximately $1 \mathrm{~kg}$ of fluorescein disodium salt (also called fluorescein or uranine) was mixed with several gallons of water and poured into the injection hole. Afterwards approximately 600 gallons ( 2.3 cubic meters) of water was used to flush the dye down the hole.

At the second site, the rhodamine WT dye was injected into a pool along a dry streambed $1,000 \mathrm{~m} \mathrm{NNW}$ of the main spring. Water was flushed into this pool, followed by approximately 1 gallon ( $\sim 0.004$ cubic meters) of rhodamine WT. Additional water was placed in the pool, causing it to overflow and follow the stream channel so that the dye would sink where it could along the channel. A total of approximately 600 gallons ( $\sim 2.3$ cubic meters) was also used at this site.

All water samplers and eluted charcoal-traps were analyzed with a Turner Designs Trilogy ${ }^{\mathrm{TM}}$ Fluorometer with modules for fluorescein and rhodamine WT. The fluorometer was calibrated with 0.1 parts per billion (ppb), $1 \mathrm{ppb}$, and $10 \mathrm{ppb}$ standards for both dyes. Calibrations were checked every day prior to analysis; the fluorometer was recalibrated as necessary. Water samples were pipetted directly into cuvettes, which were placed in the fluorometer for analysis. Charcoal traps were emptied into plastic cups and rinsed with deionized water. Approximately $12 \mathrm{~mL}$ of a solution of 95\% isopropyl alcohol, 5\% ammonium hydroxide, and supersaturated with potassium hydroxide flakes was placed in each cup with the charcoal to desorb the dye from the charcoal. The cups were capped to prevent evaporation, and then allowed to sit for approximately one hour. The resulting solution was pipetted into cuvettes to be analyzed. Each pipette and cuvette was used for only one sample before being disposed. Additionally, pairs of charcoal traps were left overnight in the lab in beakers containing $100 \mathrm{~mL}$ of known concentrations of dye before being eluted and analyzed as normal samples. This was done to note variability in readings and a relationship between dye concentrations in water and in the solution eluted from charcoal traps.

\section{Results}

There were no certain detections of fluorescein in the four recovery sites (Beaver Creek on hatchery property, the well on hatchery property, the well on farmhouse property, and the seep near Doub's Mill). Fluorescein readings at the other four sites (the main spring on hatchery property, the seep on hatchery property, and the two Beaver Creek sites on farmhouse property) were inconclusive.

The lack of certain detections of fluorescein from both the water samplers and charcoal traps indicates that under the conditions present during the study, the holes in the drainage swale NNE of the main spring do not appear to be hydraulically connected to Beaver Creek at the fish hatchery entrance, the fish hatchery well, the farmhouse well, or the seep near Doub's Mill. Results were inconclusive for the main spring and seep on hatchery property, and Beaver Creek upstream and downstream at the farmhouse.

Rhodamine WT was detected in the charcoal traps at the main spring of the hatchery, and in the well of the farmhouse. The rhodamine WT readings in the well of the hatchery are inconclusive. No evidence of rhodamine WT detection was observed from the charcoal traps at the Fish Hatchery seep, Beaver Creek on hatchery property, Beaver Creek upstream or downstream on farmhouse property, or the seep near Doub's Mill.

Background rhodamine WT readings for the charcoal traps set in the main spring on hatchery property range from $\sim 1.5-4 \mathrm{ppb}$. The charcoal traps set on March 6 and collected on March 9 returned an average rhodamine WT reading of $10 \mathrm{ppb}$. The traps set in the hatchery spring on March 9 and collected on March 13 returned an average rhodamine WT reading of $11 \mathrm{ppb}$. The rhodamine WT readings then decreased gradually until returning to the normal background range for the traps set on March 20 and later (Figure 2).

Charcoal traps set in the toilet tank fed by a well on hatchery property had background rhodamine WT readings of $\sim 1-3 \mathrm{ppb}$. The charcoal traps set on March 9 and collected on March 13 returned an average rhodamine WT reading of $5 \mathrm{ppb}$. The traps set on March 13 and collected on March 16 returned an average rhodamine reading of $5 \mathrm{ppb}$. Later readings were in the background range (Figure 2). This peak is somewhat low, compared to both background levels and to levels recorded in lab tests. Additionally, there is a wide range between the readings for the two traps placed at this site from March 9 to March 13. Therefore, these readings were inconclusive. 


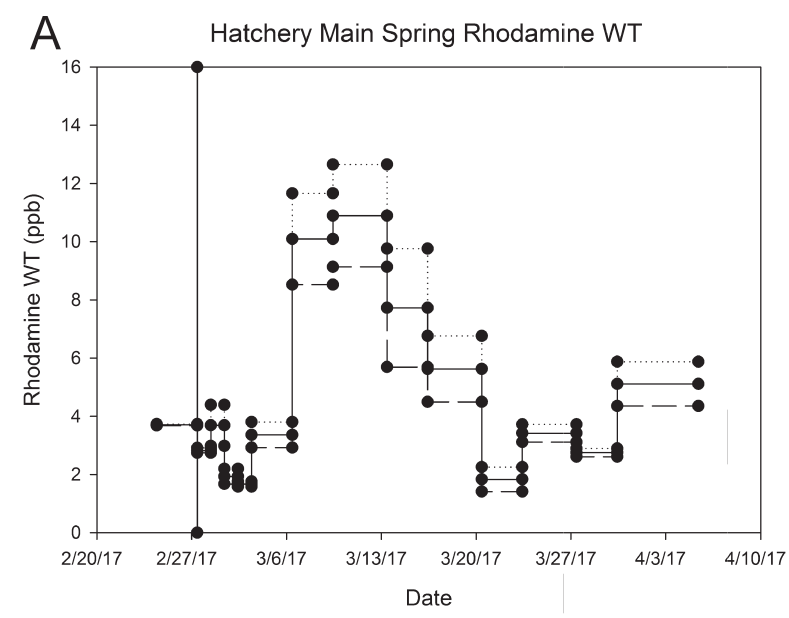

B

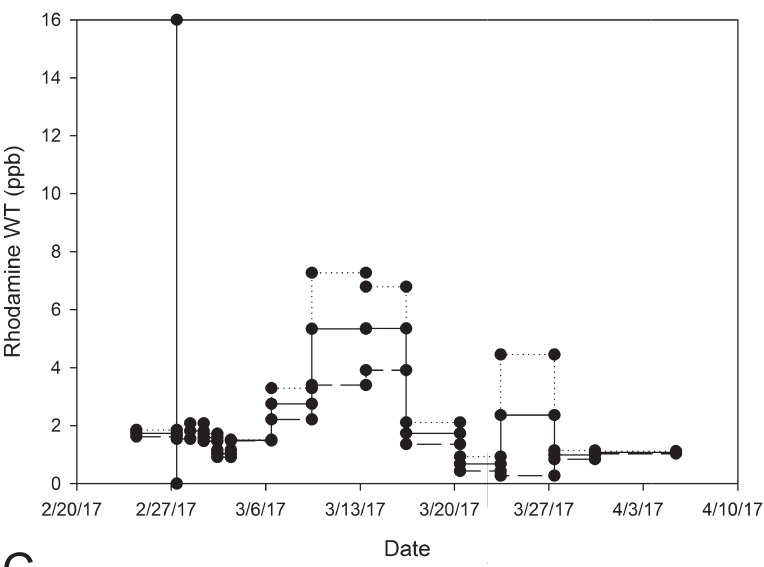

C

Farmhouse Well Rhodamine WT

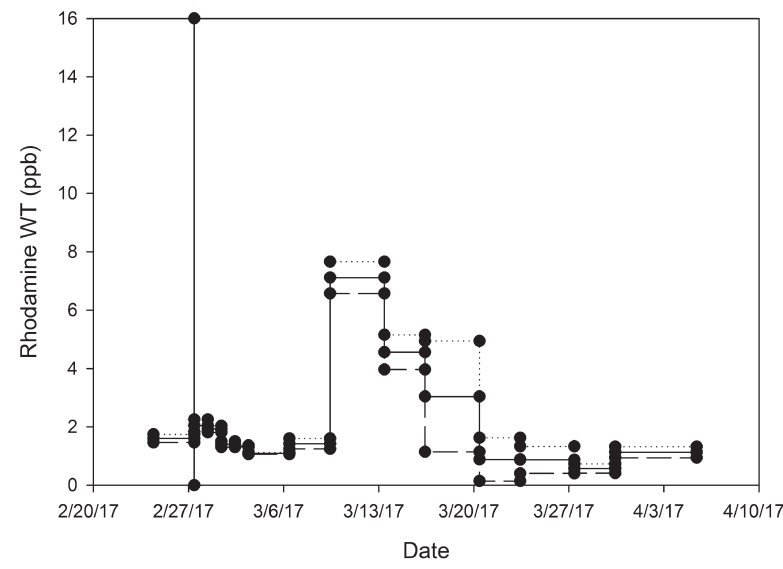

Figure 2. Timing of concentration levels of rhodamine WT recorded from charcoal traps placed in the main spring on hatchery property (A), toilet tank fed by a well on hatchery property (B), and well on farmhouse property (C). The dotted and dashed lines represent the upper and lower readings, respectively, while the solid line represents the average. The vertical lines on February 27 indicate date of dye injection.
The traps set in the toilet tank fed by a well on farmhouse property had background rhodamine WT readings of 1-2 ppb. The traps set on March 9 and collected on March 13 returned an average rhodamine WT reading of $7 \mathrm{ppb}$. The traps set on March 13 and March 16 returned decreasing but still elevated rhodamine WT readings. Traps set on March 20 and later returned readings of rhodamine WT in the background range (Figure 2).

The rhodamine WT results for the charcoal traps tested in $100 \mathrm{~mL}$ of known dye concentrations are shown in Table 1. In general, low levels of rhodamine WT in water below $1 \mathrm{ppb}$ do not lead to definitive detections of rhodamine WT in the eluted solution. However, higher levels of rhodamine WT in water lead to noticeably increasing levels of rhodamine WT in the eluted solution. The average difference in rhodamine WT readings between two traps placed in the same solution was $1 \mathrm{ppb}$. The average difference in rhodamine WT readings between two traps placed at the same field site for the same time period was $1 \mathrm{ppb}$.

The results indicate that under the conditions present during the study, the karst valley that trends northwest of the hatchery main spring is hydraulically connected to the main spring on hatchery property, to the farmhouse well, and possibly to the hatchery well (Figure 3).

\section{RESISTIVITY AND KARST AT APH}

An electrical resistivity study was conducted near the APH to evaluate the potential for bedrock voids along the northwest trending cross fault. Electrical resistivity (ER) imaging can be an effective method for identifying subsurface water- and air-filled voids when there is a strong contrast in conductivity with the surrounding bedrock (Zhou and others, 2002; Zhu and others, 2001). ER injects a direct current into the ground between

\begin{tabular}{|l|c|c|c|}
\hline Solution & $\begin{array}{c}\text { Sample } \\
1(\mathrm{ppb})\end{array}$ & $\begin{array}{c}\text { Sample } \\
2(\mathrm{ppb})\end{array}$ & $\begin{array}{c}\text { Average } \\
(\mathrm{ppb})\end{array}$ \\
\hline Blank (deionized water) & 0.8 & 1.0 & 0.9 \\
\hline $0.1 \mathrm{ppb}$ rhodamine WT & 1.0 & 2.5 & 1.8 \\
\hline $0.5 \mathrm{ppb}$ rhodamine WT & 0.7 & 1.6 & 1.2 \\
\hline 1 ppb rhodamine WT & 0.9 & 3.2 & 2.0 \\
\hline $10 \mathrm{ppb}$ rhodamine WT & 3.3 & 3.2 & 3.3 \\
\hline $100 \mathrm{ppb}$ rhodamine WT & 19.7 & 18.9 & 19.3 \\
\hline
\end{tabular}

Table 1. Concentrations of rhodamine WT measured in solution eluted from charcoal traps left overnight in $100 \mathrm{~mL}$ of water with known initial dye concentration. 


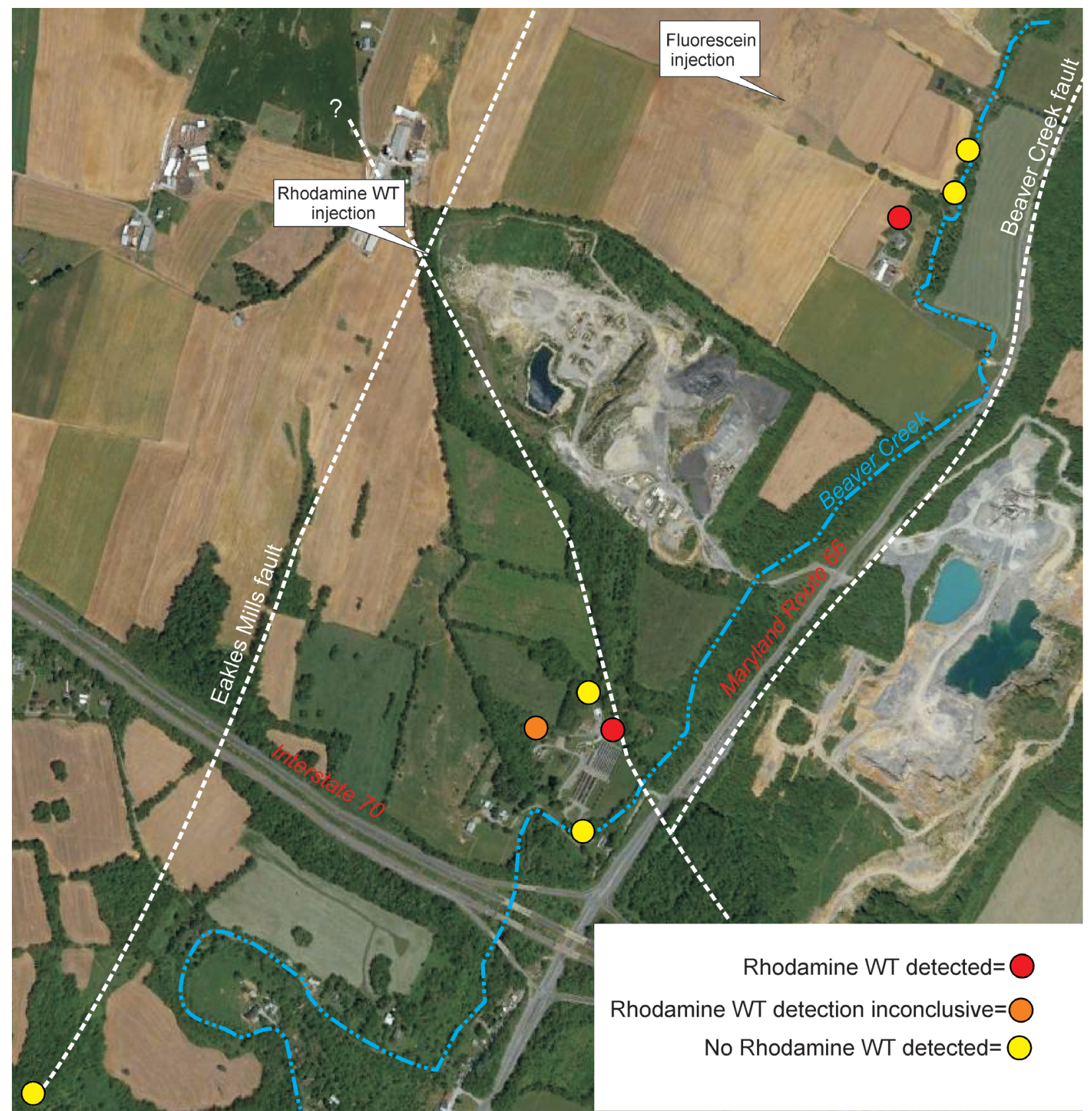

Figure 3. Summary results of dye tracing study surrounding the Albert Powell Hatchery, Washington County Maryland. Google Earth base image date 5/25/13.

two metal electrodes and then measures the potential field between additional nearby electrodes to model changes in resistivity around subsurface targets. The measured potential depends on the resistivity of the materials through which the current is conducted, which varies with geologic factors such as lithology, porosity, and saturation (Table 2). Modeled resistivity profiles then allow geologic and hydrologic interpretation and comparison with ground truth data.

\begin{tabular}{|l|c|}
\hline Material & $\begin{array}{c}\text { Resistivity from wet to dry } \\
\text { (Ohm·meters) }\end{array}$ \\
\hline Sandstone & $10-6000$ \\
\hline Shale & $30-3000$ \\
\hline Limestone & $70-7000$ \\
\hline Dolomite & $500-7000$ \\
\hline Clay & $1-100$ \\
\hline Groundwater (fresh) & $10-100$ \\
\hline Sea water & 0.2 \\
\hline Air & $>10,000$ (Theoretically infinite) \\
\hline
\end{tabular}

Table 2. Typical resistivity values of earth materials in the APH study area. Adapted from Loke, 2016. 
ER surveys employ an array of electrodes connected with electrical cable and arranged either in a straight line (2D surveys and quasi-3D surveys) or a grid (3D surveys). Electrode pairs are automatically measured by means of a switchbox and resistivity meter. The depth of investigation is approximately $20 \%$ of the maximum length of survey, while resolution is estimated to be one half of the electrode spacing. MGS staff initially conducted electrical resistivity surveys perpendicular to the line projected for the cross-fault (Figure 4), using 28 electrode arrays at a $3-\mathrm{m}$ electrode spacing, for a maximum length of $81 \mathrm{~m}$, a depth of investigation of approximately $23 \mathrm{~m}$, and resolution of $1.5 \mathrm{~m}$. The electrode spacing and maximum survey length were

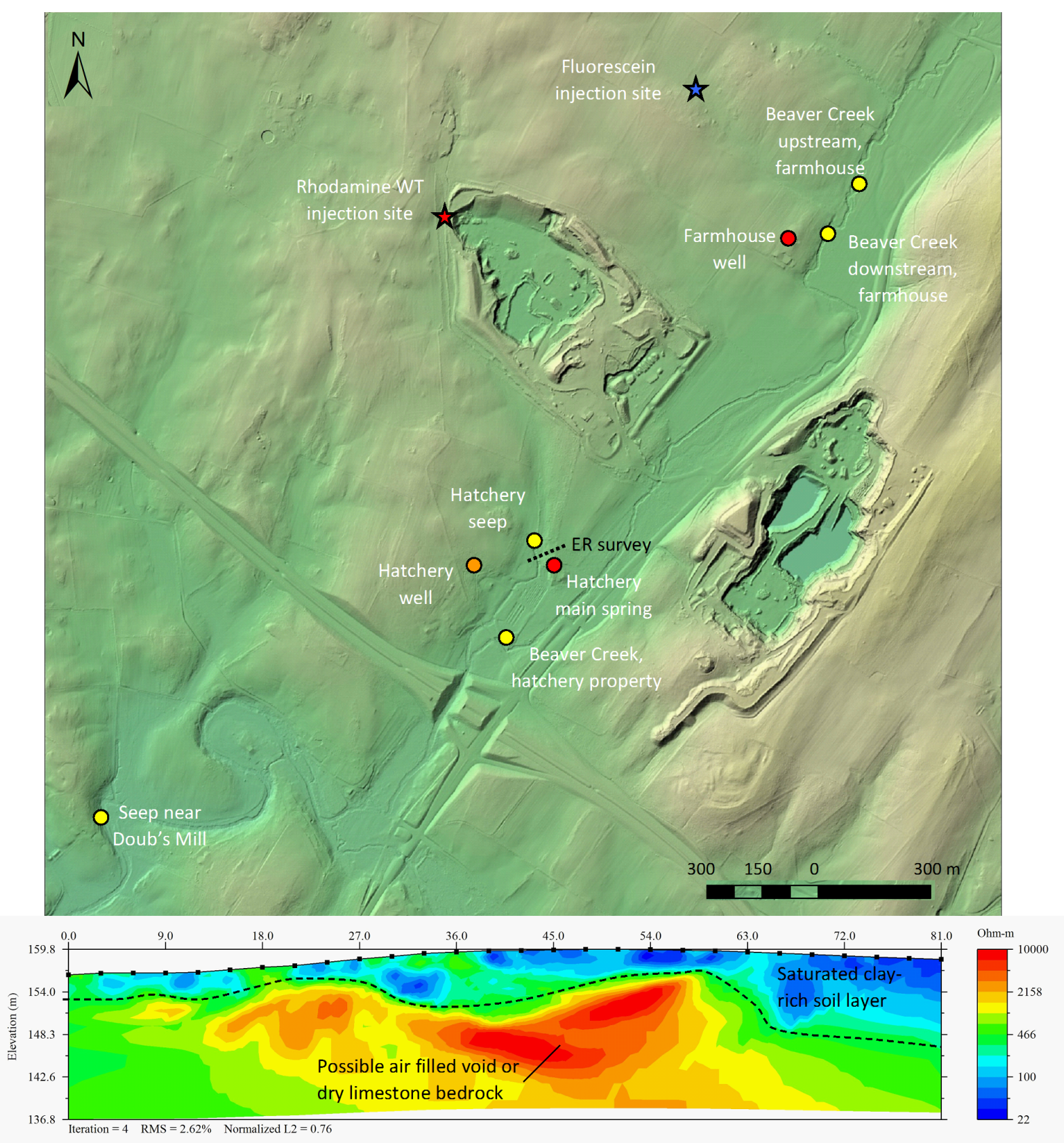

Figure 4. Location of ER survey relative to APH main spring and dye tracing sites on background LiDAR-derived hillshade image. Beneath it is inverted resistivity profile from the ER survey showing highly resistive anomaly. 
chosen to strike a balance between maximizing the exploration depth while maintaining a degree of resolution able to define both small and large voids in the bedrock. A dipole-dipole array was chosen for the electrode configuration as it has been shown effective in mapping both air and water-filled karst voids (Zhou and others, 2002; Zhu and others, 2011). While resistivity data were collected, a survey-grade global positioning system (GPS) survey was conducted of all electrode positions for each array. The elevation data were used for advanced processing to correct for variations in topography along the survey line. An Advanced Geosciences, Inc. (AGI) SuperSting R8/ IP/SP electrical imaging system was used to collect the data and EarthImager-2D ${ }^{\mathrm{TM}}$ software was used to process the data. Results of the ER survey (Figure 4) showed a thin low resistivity layer near the surface corresponding to values for a saturated clay-rich soil. A highly resistive area occurred in the middle of the profile from 6-14 $\mathrm{m}$ in depth and may indicate an air-filled void, dry limestone and dolomitic bedrock, or a combination of the two. Further ER surveys using expanded 2D, quasi-3D, and 3D arrays will increase the depth and width of the imaging and may better constrain the location and orientation of this anomaly.

\section{DISCUSSION}

Rhodamine WT readings in charcoal traps at the main spring of the hatchery and the toilet tank fed by wellwater on the farmhouse property both increased to several times background levels in early March 2017, with the increases being greater than the usual variability between charcoal traps set at the same site. While the dye trace conducted for this study established a connection between the spring and the rhodamine WT injection site, this does not necessarily establish that site as the source of the turbidity observed at the spring. However, it may implicate the northwest trending cross fault as a possible course along which some of the dye migrated.

The Maryland Geological Survey also reviewed precipitation data and the quarry blasting schedule, and found no evidence to associate the turbidity events with either precipitation or blasting events.

The fact that the 2004 and 2016-17 turbidity events all occurred within the late fall and early winter may reflect a proclivity of these events at that time of the year. The lowest monthly mean spring flow occurred in November (3074 gallons per minute / 698 cubic meters per hour) based on a period of record from 1987-1997 whereas the highest monthly mean spring flow was in April (4187 gallons per minute/ 951 cubic meters per hour) (James and others, 1999). The lowered water table at that time of the year may have increased the potential of these presumably subsurface sedimentation events. Due to the complexity of karst terrain, connections between sinkholes and springs may vary depending on water level. During times of high flow, hydraulic pathways that are dry at low flow may be active (Kentucky Natural Resources and Environmental Protection Cabinet, 1991).

As a proxy for determining water levels in the shallow aquifer, stream flow for eastern Washington County was examined. The stream flow, as recorded by a gauging station downstream from the hatchery (Figure 5), illustrates that the October 2016 through January 2017 records suggest diminished surface water flow. Concomitantly, the hatchery spring was flowing at approximately 1900 gallons per minute ( 432 cubic meters per hour).

If it is assumed that low water table and greatly reduced subterranean flow affects karst conduit character, any slumping or widening within the conduits might have had a greater effect on the reduced level of karst flow. Because of the complexity of karst systems, additional and different hydraulic pathways could be in effect during higher flow regimes. Groundwater divides in karst areas are known to change with different conditions, and operate as three-dimensional flow systems where overflow routes can convey water to different discharge

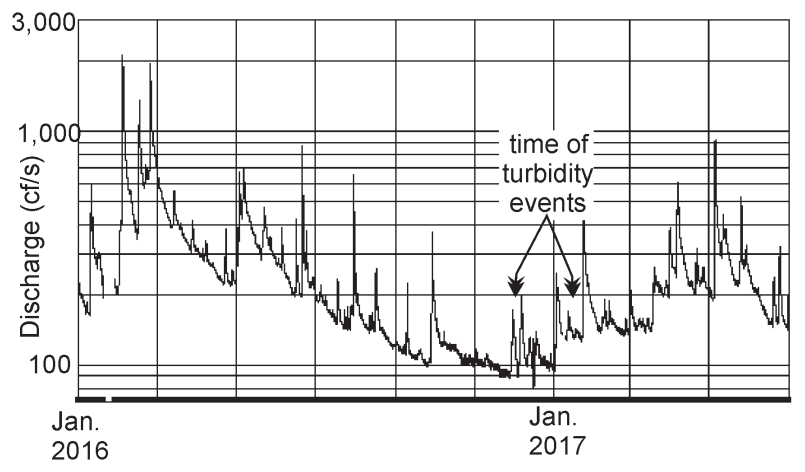

Figure 5. Timing of turbidity events at APH and stream flow of nearby Antietam Creek for the period from January 2016 to July 2017. USGS gauging station 01619500 is approximately 18 $\mathrm{km}$ southwest and down-stream from main hatchery spring. 
points depending on the hydrologic conditions (White, 1993; Meiman and others, 2001).

\section{ACKNOWLEDGEMENTS}

We would like to thank Marshall Brown and Kenneth Booth of APH for help in organizing and conducting this study. Kyle Walker (BlueGrass Materials Company) provided permission and access to the adjacent quarry properties for dye injection. The Maryland Forest Service provided and drove water trucks for dye injection. The Martz and Martin families provided access to their properties for injection and monitoring. The use of trade names and product names in this report is for identification purposes only, and does not constitute endorsement by the Maryland Geological Survey or other agencies associated with this study.

\section{REFERENCES}

Brezinski DK. 1992. Lithostratigraphy of the western Blue Ridge cover rocks in Maryland. Maryland Geological Survey Reports of Investigation 55, 69 p.

Brezinski DK, Bell SK. 2009. Geologic Map of the Funkstown Quadrangle, Washington County, Maryland. Maryland Geological Survey Digital Geologic Map, scale 1:24,000.

Brezinski DK, Fauth JL. 2009. Geologic Map of the Myersville and Smithsburg Quadrangles, Frederick and Washington Counties, Maryland. Maryland Geological Survey Digital Geologic Map, scale 1:24,000.

Duigon MT. 2009. Phase 2 study of the area contributing groundwater to the spring supplying the A.M. Powell State Fish Hatchery, Washington County, Maryland. Maryland Geological Survey Open-File Report No. 2008-02-18, 32 p.

James RW, Helinsky BM, Tallman AJ. 1999. Water resources data, Maryland and Delaware, water year 1997. Surface-water data: U.S. Geological Survey: 1.

Kentucky Natural Resources and Environmental Protection Cabinet, 1991. Groundwater and karst. Kentucky Department for Environmental Protection, Division of Water, $76 \mathrm{p}$.

Loke MH. Tutorial: 2-D and 3-D electrical imaging surveys [Internet]. 2016. Penang, Malaysia: GeoTomo LLC; [cited 2017 Sept 19]. Available from: http://www.geotomosoft.com/downloads. php.

Meiman J, Groves C, Herstein S. 2001. In-cave dye tracing and drainage basin divides in the Mammoth Cave karst aquifer, Kentucky. in Kuniansky E, ed., 2001, U.S. Geological Survey
Karst Interest Group Proceedings, WaterResources Investigations Report 01-4011, p. 179-185.

Reger JP, Cleaves ET. 2008. Physiographic map of Maryland. Maryland Geological Survey, scale $1: 250,000$.

Water level monitoring data. 2004. H.B. Mellott Estate: Groundwater Sciences Corporation; plate 1. Unpublished.

White WB. 1993, Analysis of karst aquifers. in Alley WM, ed., Regional ground-water quality: New York, Van Nostrand Reinhold, p. 471-489.

Zhou W, Beck BF, Adams AL. 2002. Effective electrode array in mapping karst hazards in electrical resistivity tomography. Environmental Geology 42: 922-928.

Zhu J, Currens JC, Dinger JS. 2011. Challenges of using electrical resistivity to locate karst conduits - A field case in the Inner Bluegrass Region, Kentucky. Journal of Applied Geophysics 75: 523-530. 